\title{
AEG-1 associates with metastasis in papillary thyroid cancer through upregulation of MMP2/9
}

\author{
LEI-LEI HUANG ${ }^{*}$, ZHUO WANG ${ }^{*}$, CHUANG-JIE CAO*, ZUN-FU KE, FEN WANG, \\ RAN WANG, CAN-QIAO LUO, XIAOFANG LU and LIAN-TANG WANG

\begin{abstract}
Department of Pathology, The First Affiliated Hospital of Sun Yat-Sen University, Guangzhou, Guangdong 510080, P.R. China
\end{abstract}

Received December 23, 2016; Accepted June 29, 2017

DOI: 10.3892/ijo.2017.4074

\begin{abstract}
Astrocyte elevated gene-1 (AEG-1), known as an oncogene, is overexpressed in various cancers and implicated in tumor progression and metastasis. However, its functional significance and underlying molecular mechanisms in thyroid cancer remain to be elucidated. In the present study, we detected the potential function of AEG-1 in papillary thyroid cancer (PTC). We also investigated the relation between AEG-1 and matrix metalloproteases (MMP)2 and 9 through immunohistochemistry, western blotting, real-time PCR, immunofluorescence staining, zymography and co-immunoprecipitation (Co-IP). We found that overexpression of AEG-1 in PTC was positively correlated with lymph node metastasis and MMP2/9 expression. Knockdown of AEG-1 reduced the capacity of migration and invasion through downregulation of MMP2/9 in thyroid cancer cells. Furthermore, we firstly found that AEG-1 interacted with MMP9 in thyroid cancer cells. AEG-1 was associated with the activation of the nuclear factor $\kappa \mathrm{B}(\mathrm{NF}-\kappa \mathrm{B})$ signaling pathways in thyroid cancer cells. Overall, our results for the first time showed that AEG-1 interacted with MMP9 in thyroid cancer cells and AEG-1 expression was closely associated with progression and metastasis of papillary thyroid cancer. AEG-1 might be a potential therapeutic target in papillary thyroid cancer.
\end{abstract}

\section{Introduction}

Thyroid cancer is one of the fastest growing diagnoses; more cases of thyroid cancer are found every year than all leukemias and cancers of the liver, pancreas, and stomach (1). Papillary thyroid cancer (PTC) represents the most common

Correspondence to: Professor Lian-Tang Wang, Department of Pathology, The First Affiliated Hospital of Sun Yat-Sen University, 58 Zhongshan Road II, Guangzhou, Guangdong 510080, P.R. China E-mail: wanglt@mail.sysu.edu.cn

*Contributed equally

Key words: astrocyte elevated gene-1, papillary thyroid cancer, MMP2, MMP9, metastasis type of thyroid cancer, accounting for $80-85 \%$ of all thyroid cancer cases. The majority of patients with thyroid cancer generally have good prognoses after appropriate treatment. Unfortunately, $20-50 \%$ of patients of PTC are diagnosed with lymph node metastasis (2). At the same time, the recurrence of differentiated thyroid cancer is up to $30 \%$ after initial treatment at 30 years of follow-up (3). Retrospective population-based studies have illustrated that cervical lymph node metastases conferred independent risk in all patients with follicular carcinoma and in those patients with papillary carcinoma aged $\geq 45$ years (4). Therefore, it is urgent to identify new predictive biomarkers for lymph node metastasis and novel therapeutic targets for thyroid cancer.

Astrocyte-elevated gene-1 (AEG-1), also known as Metadherin or Lyric, was originally identified as a novel gene induced by human immunodeficiency virus (HIV)-1 or tumor necrosis factor (TNF)- $\alpha$ in primary human fetal astrocytes (PHFA) $(5,6)$. Numerous recent studies have revealed that AEG-1 is markedly overexpressed in various types of human cancer, including hepatocarcinoma, gastrointestinal cancer and malignant glioma $(7,8)$. AEG-1 played an important role in transformation, proliferation, cell survival, evasion of apoptosis, migration and invasion, metastasis, angiogenesis, chemoresistances and epithelial-mesenchymal transition (9). For example, some researcher identified two novel factors, AKR1C2 (positive factor) and NF1 (negative factor), as the AEG-1 downstream players in the process of metastasis in liver cancer through deep sequencing and expression regulation analysis in liver cancer cells (10).

AEG-1 is associated with pro-tumorigenic signal transduction pathways, including AKT, NF- $\mathrm{BB}, \mathrm{PI} 3 \mathrm{~K}-\mathrm{AKT}$ and Wnt pathways to regulate invasion and metastasis of carcinoma cells $(11,12)$. Upregulation of AEG-1 could induced the transcriptional activity and the cytoplasm/nucleus translocation of NF- $\mathrm{NB}$; and inhibition of NF- $\mathrm{BB}$ markedly reversed AEG-1-induced agar cloning efficiency and matrigel invasion in Hela cells and human glioma cells $(13,14)$. Aberrant expression of AEG-1 affects the migration and invasiveness of non-small cell lung cancer cell lines via the NF- $\kappa \mathrm{B}$ and PI3K-AKT pathways (12). Recombinant AEG-1 activated Wnt signaling, and its stimulatory effects on squamous cell carcinoma of tongue cell invasiveness and epithelialmesenchymal transition were reversed by an anti-Wnt5a 
neutralizing antibody or by inhibition of Rac1 or ROCK (15). The evidence suggested that AEG-1 was an important oncogene contributing to the progression and metastasis of human cancers. However, the role of AEG-1 is not known in thyroid cancer.

In the present study, we found that AEG-1 was observably overexpressed in thyroid cancer and positively correlated with lymph node metastasis. Additionally, AEG-1 siRNA could significantly decrease the migration and invasion by modulating MMP2 and MMP9 activity in thyroid cancer cells. Moreover, for the first time the interaction between AEG-1 and MMP9 was found, which might be a possible mechanism of AEG-1-mediated tumor cell migration and invasion. NF- $\mathrm{B}$ signaling pathways might be involved in this process.

\section{Materials and methods}

Cell lines. Human thyroid cancer cell lines BCPAP and SW579 (human thyroid carcinoma cell line) were obtained from Cell Banks at the department of Pathology, Zhongshan School of Medicine, Sun Yat-sen University, Guangzhou, China [originally from American type culture collection (ATCC)]. BCPAP (16) was derived from an thyroid papillary carcinoma and SW579 (17) from a thyroid cancer with squamous carcinoma differentiation. Cells were cultured in RPMI-1640 media (Gibco, Grand Island, NY, USA) supplemented with 10\% fetal bovine serum (Hyclone, Tauranga, New Zealand), $100 \mu \mathrm{g} / \mu \mathrm{l}$ streptomycin and $100 \mu \mathrm{g} / \mu \mathrm{l}$ penicillin in humidified incubator at $37^{\circ} \mathrm{C}$ with $5 \% \mathrm{CO}_{2}$.

Tissue specimen. Tissue specimens and controls were obtained from patients who underwent surgery at the First Affiliated Hospital at Sun Yat-sen University from 2006 to 2008. Paraffin-embedded tissue blocks were retrieved from 204 pairs of PTC tissues, their adjacent non-cancerous tissues (ANT), and 83 corresponding metastatic PTC tissues in lymph nodes (due to their tiny size, 2 corresponding lymph node metastatic PTC tissues were unavailable). Moreover, eight pairs of fresh PTC tissues and adjacent non-cancerous tissues (ANT) were obtained from the Department of Vacular and Thyroid Surgery, the First Affiliated Hospital, Sun Yat-sen University. Samples were collected immediately after surgical removal and snap-frozen in liquid nitrogen and conserved at $-80^{\circ} \mathrm{C}$. This study was approved by the Research Ethics Committee of The First Affiliated Hospital at Sun Yat-sen University.

The histopathology of the disease was determined according to the criteria of the World Health Organization by two pathologists. Pathological staging was done according to the tumour-node-metastasis (TNM) classification of the Union for International Cancer Control (UICC). For the research purposes of these clinical materials, prior patient's consents and approval from the Institutional Research Ethics Committee were obtained. Detailed clinical information about these patients, including age, gender, TNM stage, tumor size, lymph node metastasis and distant metastasis is summarized in Table I.

Tissue microarray. Tissue microarrays (TMAs) were constructed according to standard procedures (Unitma Co.,
Ltd., Seoul, Korea). Briefly, utilizing the hematoxylin and eosin (H\&E) sections as templates, representative areas of each case were identified and marked on a section of the donor block. Approximately 3-mm-thick (2-mm diameter) tissue cylinders were punched from each donor paraffin block using Quick-Ray tissue microarray instrument (Unitma Co., Ltd.). The donor cores were placed into the corresponding recipient block holes. To better represent each case, two tumor and two normal tissue cores were punched from each case. After construction, recipient blocks were pressed down by a slide for a moment to flatten the surface, put into embedding molds and incubated in an oven at $60^{\circ} \mathrm{C}$ for $30 \mathrm{~min}$, then removed. Serial $4-\mu \mathrm{m}$ sections were cut with a Leica microtome (Leica Microsystems; Wetzlar, Germany) and mounted onto polylysine-coated slides.

Immunohistochemistry. Sections $(4 \mu \mathrm{m})$ were deparaffinized, rehydrated in serially graded ethanol, heated in citric buffer ( $\mathrm{pH}$ 6.0) once for $15 \mathrm{~min}$ in a microwave oven for antigen retrieval, and blocked with $3 \%$ hydrogen peroxide. They were then labeled with anti-AEG-1 antibody (1:500, Abnova), antiMMP2 antibody (1:300, Abgent) and anti-MMP9 antibody (1:200, Abgent) at $4^{\circ} \mathrm{C}$ overnight. The next day, after washing with phosphate-buffered saline (PBS), the sections were incubated with EnVision-HRP secondary antibody (Dako, Carpinteria, CA, USA) for $30 \mathrm{~min}$ at $37^{\circ} \mathrm{C}$ in a water bath, washed with PBS, stained with $0.5 \%$ diaminobenzidine and counterstained with Mayer's hematoxylin, then air dried, and mounted with resinene.

Evaluation of immunohistochemistry. The immunohistochemical staining in TMAs of cancerous and adjacent tissues was subjected to microscope and image analysis (Nanozoomer, Hamamatsu, Japan). Brown-yellow granules in the cytoplasm were recorded as positive immunostaining. The areas from both cancer and its adjacent normal tissue were selected for analysis. The intensity of the staining signal was measured and documented by using the Image-Pro Plus 6.0 image analysis software (Media Cybernetics, Inc., Silver Spring, MD, USA). The mean densitometry of the digital image (x400) was designated as representative IHC staining intensity. In the equal areas, the positive areas and the average optical density (AOD) were detected, respectively. The staining positive index $=$ positive area $x$ average optical density. The signal density of tissue areas from three randomly selected visions were counted in a blinded manner and subjected for statistical analysis.

RNA interference. Cells were seeded in 6-well plate wells with $3 \times 10^{5}$ cells per well. After the density of cells growing to approximately $50 \%$, cells were starved in medium without serum for $3 \mathrm{~h}$. By mixing $50 \mathrm{nM}$ siRNA with $5 \mu \mathrm{l}$ Lipofectamine RNAiMAX (Invitrogen, Carlsbad, CA, USA) in $500 \mu \mathrm{l}$ OPTI-MEM (Gibco) at room temperature for at least $20 \mathrm{~min}$, cationic lipid complex were prepared and then were added to the cells. After $6 \mathrm{~h}$ of incubation, the media were replaced with fresh medium and the cells were cultured for another 24 or $48 \mathrm{~h}$ after transfection, and then were harvested for analysis. The siRNA specifically for AEG-1 and scrambled siRNA as negative control were purchased from (Ruibo, Guangzhou, China). The following oligonucleotides for AEG-1: sense 5'-GGU CUC 
Table I. AEG-1 expression in PTC and their relation with clinicopathological features of PTC.

\begin{tabular}{|c|c|c|c|c|}
\hline Variable & Cases (n) & $\%$ & Expression level of AEG-1 & P-value \\
\hline Age (years) & 8-78 (mean age: 39$)$ & & & 0.186 \\
\hline$<45$ & 141 & 69.1 & $0.1540 \pm 0.0498$ & \\
\hline$\geq 45$ & 63 & 30.9 & $0.1435 \pm 0.0563$ & \\
\hline Sex & & & & 0.226 \\
\hline Male & 50 & 24.5 & $0.1543 \pm 0.0520$ & \\
\hline Female & 154 & 75.5 & $0.1496 \pm 0.0521$ & \\
\hline Tumor size $(\mathrm{cm})$ & & & & 0.164 \\
\hline$\leq 2$ & 122 & 59.8 & $0.1466 \pm 0.0521$ & \\
\hline$>2$ & 82 & 40.2 & $0.1569 \pm 0.0514$ & \\
\hline TNM stage & & & & 0.233 \\
\hline I-II & 184 & 90.2 & $0.1493 \pm 0.0512$ & \\
\hline III-IV & 20 & 9.8 & $0.1639 \pm 0.0584$ & \\
\hline Lymph node metastasis & & & & $0.007^{\mathrm{a}}$ \\
\hline Present & 85 & 41.7 & $0.1622 \pm 0.0538$ & \\
\hline Absent & 119 & 58.3 & $0.1425 \pm 0.0492$ & \\
\hline Distant metastasis & & & & 0.284 \\
\hline Yes & 3 & 1.5 & $0.1827 \pm 0.0589$ & \\
\hline No & 201 & 98.5 & $0.1503 \pm 0.0519$ & \\
\hline
\end{tabular}

${ }^{\mathrm{a}} \mathrm{P}<0.05$.

AGA UGA UGA UAA ATT-3' and anisense: 5'-UUU AUC AUC AUC UGA GAC CTT-3'; Control siRNA: sense 5'-UUC UCC GAA CGU GUC ACG UTT-3' and anisense: 5'-ACG UGA CAC GUU CGG AGA ATT-3'.

RNA extraction and quantitative RT-PCR. Total RNA from fresh tissues was extracted using TRIzol reagent (Invitrogen) according to the manufacturer's instruction, and the RNA from cells was extracted using RNApure Tissue kit (CWBiotech, Beijing, China). RNA ( $2 \mu \mathrm{g})$ from each sample was used for cDNA synthesis (Roche, Basel, Switzerland) and quantitative real-time PCR analysis (Roche). The primers for amplification were: AEG-1 sense 5'-CGA GAA GCC CAA ACC AAA TG-3', antisense 5'-TGG TGG CTG CTT TGC TGT T-3'; MMP2 sense 5'-CTG GGA GCA TGG CGA TGG ATA-3', antisense 5'-GGA AGC GGA ATG GAA ACT TG-3'; MMP9 sense 5'-GCC ATG TCT GCT GTT TTC TAG AGG-3', antisense 5'-CAC ACT CCA GGC TCT GTC CTC TTT-3'. GADPH (sense 5'-GTG GAC CTG ACC TGC CGT CT-3', antisense 5'-GGA GGA GTG GGT GTC GCT GT-3') was used as an internal control. Target gene expression was calculated using $\Delta \Delta \mathrm{Ct}$ and comparative methods after normalization to GAPDH expression. All experiments were performed in triplicates.

Protein extraction and western blotting. Cells were lysed in RIPA buffer, agitated for $30 \mathrm{~min}$ at $4^{\circ} \mathrm{C}$, sonicated for $15 \mathrm{sec}$ using sonic oscillator and centrifuged at $14000 \mathrm{rpm}$ for $15 \mathrm{~min}$. The concentration of total proteins was determined using BCA method. Total proteins $(30 \mu \mathrm{g})$ in equal volume were then denatured and loaded on $10 \%$ SDS polyacrylamide gels for separation. The proteins were transferred onto polyvinylidene difluoride membranes that were subsequently blocked in 5\% nonfat milk in TBST. The membranes were incubated with primary antibodies including rabbit antiAEG-1 (1:4000, Abnova), mouse anti-MMP2 (1:1000, Abgent), rabbit anti-MMP9 (1:1500, Abgent), rabbit anti-p65 (1:1000), rabbit anti-phospho-p65 (1:1000), and rabbit anti-GAPDH (1:2000) (Cell Signaling Technology, Danvers, MA, USA) at $4^{\circ} \mathrm{C}$ overnight. After washing with TBST, the membranes were probed with secondary antibody HRP-conjugated goat antirabbit (1:5000, Cell Signaling Technology) or goat anti-mouse (1:4000, CWBiotech) and visualized by enhanced chemiluminescence. The gray scale value was calculated and analyzed by using the Image-Pro Plus 6.0 image analysis software.

Immunofluorescence staining. BCPAP and SW579 cell lines were transfected with AEG-1 siRNA and scrambled siRNA as negative control. At $24 \mathrm{~h}$ after transfection, cells were rinsed with PBS two times and fixed in $4 \%$ paraformaldehyde for $10 \mathrm{~min}$ at room temperature, washed three times with PBS, then permeabilized in $0.4 \%$ Triton X-100 in PBS for 15 min at room temperature. Cells were blocked in $5 \%$ bovine serum albumin in PBS for $45 \mathrm{~min}$ at $37^{\circ} \mathrm{C}$ and then incubated with AEG (1:500, Abnova), MMP2 (1:300, Abgent), and MMP9 (1:200, Abgent) at $4^{\circ} \mathrm{C}$ overnight. After three 5-min washes in PBS, TRITCconjugated goat anti-rabbit IgG secondary antibody (1:400) or FITC-conjugated goat anti-mouse IgG secondary antibody (1:400) (EarthOx, San Francisco, CA, USA) were used for $30 \mathrm{~min}$. Staining with diamidino phenylindole was performed 

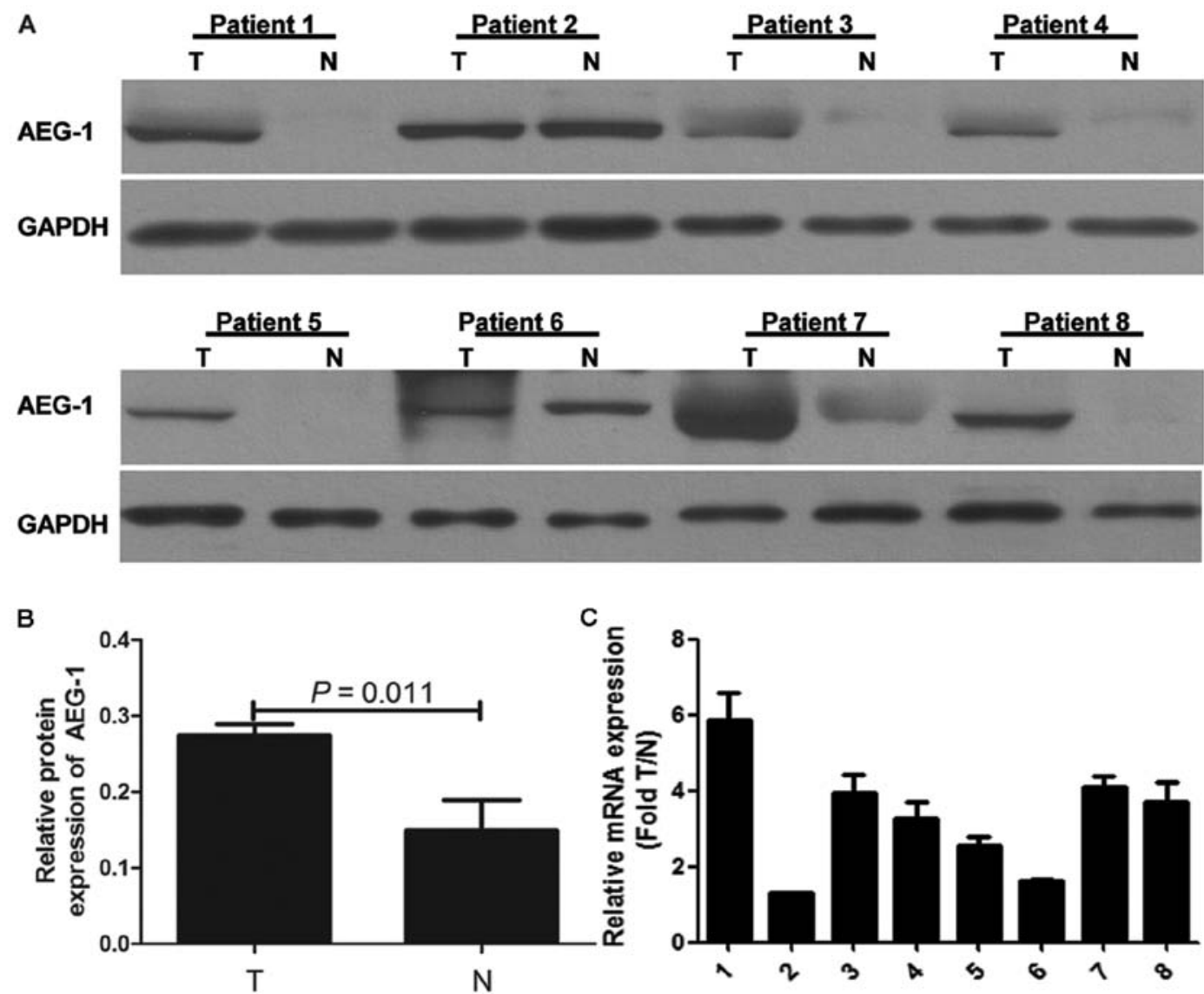

Figure 1. AEG-1 expression in primary PTC. (A) AEG-1 protein expression was elevated in eight pairs of PTC (T) compared with that in adjacent non-cancerous tissues $(\mathrm{N})$ by western blot analysis. (B) The gray intensity of AEG-1 of PTC tissue is higher than ANT (P=0.011). (C) AEG-1 mRNA expression was elevated in eight pairs of PTC compared with ANT by real-time PCR. Target gene expression was calculated using $\Delta \Delta C t$ and comparative methods after normalization to GAPDH expression. Each experiment was performed three times in triplicate.

at a dilution of 1:1000 in PBS for 5 min to visualize the nuclei. Slides were mounted using $90 \%$ glycerine and visualized using an Olympus BX51 fluorescence microscope (Olympus, Tokyo, Japan).

Transwell cell invasion and migration assay. For invasion assay, BCPAP and SW579 transfected with AEG-1 siRNA or Scrambled siRNA were trypsinized and resuspended to a density of $1 \times 10^{5} / \mathrm{ml}$ in serum-free RPMI-1640 medium. A $200 \mu 1$ cell suspension was plated into the top side of polycarbonate Transwell filter coated with $30 \mathrm{mg} / \mathrm{cm}^{2}$ of Matrigel in the upper chamber of the BioCoat ${ }^{\mathrm{TM}}$ invasion chambers (BD Bioscience, Bedford, MA, USA). After incubated at $37^{\circ} \mathrm{C}$ for $36 \mathrm{~h}$, cells on the upper chamber were removed by wiping gently with cotton swabs. Cells on the lower membrane surface were fixed in $1 \%$ paraformaldehyde for $20 \mathrm{~min}$, stained with $0.3 \%$ Crystal Violet solution for $20 \mathrm{~min}$, and then counted (five high-power fields per chamber). The migration assay was performed the same as the invasion assay except that no matrigel was added to the transwell membrane. Both experiments were performed in triplicate and the data were presented as mean \pm standard deviation $(\mathrm{SD})$.

Zymography. Cells were cultured in serum-free medium for $24 \mathrm{~h}$ after $48 \mathrm{~h}$ transfection. The conditioned medium was concentrated by using Amicon Ultra- 15 centrifugal filter devices
(Millipore, Boston, MA, USA) to preserve the supernatant. Gelatin zymography required $20 \mu \mathrm{g}$ protein of culture media separated by electrophoreses on an $8 \%$ SDS-polyacrylamide gel (SDS-PAGE) with $0.1 \%$ gelatin and without reducing agent at $4^{\circ} \mathrm{C}$. After electrophoresis, gels were washed in $3 \%$ Triton 2 times on the shaker for $30 \mathrm{~min}$ at room temperature to remove the SDS. Gels were incubated for $48 \mathrm{~h}$ at $37^{\circ} \mathrm{C}$ in incubation buffer then stained for $2 \mathrm{~h}$ with $0.1 \%$ Coomassie blue R250 (Sigma, USA) dissolved in $10 \%$ acetic acid and $40 \%$ methanol in $\mathrm{H}_{2} \mathrm{O}$. Following the instructions of the gelatin zymography regent (Applygen, Beijing, China), clear digested bands appeared and then was photographically scanned.

Co-immunoprecipitation (Co-IP). Co-IP was operated as instructed by the manufacturer by using the Pierce Co-Immunoprecipitation kit (Thermo Fisher Scientific, Waltham, MA, USA). In brief, cells were lysed in immunoprecipitation buffer. Total cell lysate $(1 \mathrm{mg}), 30 \mu \mathrm{g}$ of anti-AEG-1 antibody or normal IgG, and $50 \mu \mathrm{l}$ of the resin slurry were mixed and transferred to the Pierce Spin Column. The mixture was incubated overnight at $4^{\circ} \mathrm{C}$ with continuous agitation. After washing three times with $200 \mu \mathrm{l}$ of IP Lysis/Wash Buffer, the immunocomplexes were eluted by adding $60 \mu \mathrm{l}$ of Elution Buffer. The eluted sample was fractionated by sodium dodecyl sulfate-polyacrylamide gel electrophoresis, and western blot analysis was used to detect MMP2 and MMP9 with anti-MMP2 
A
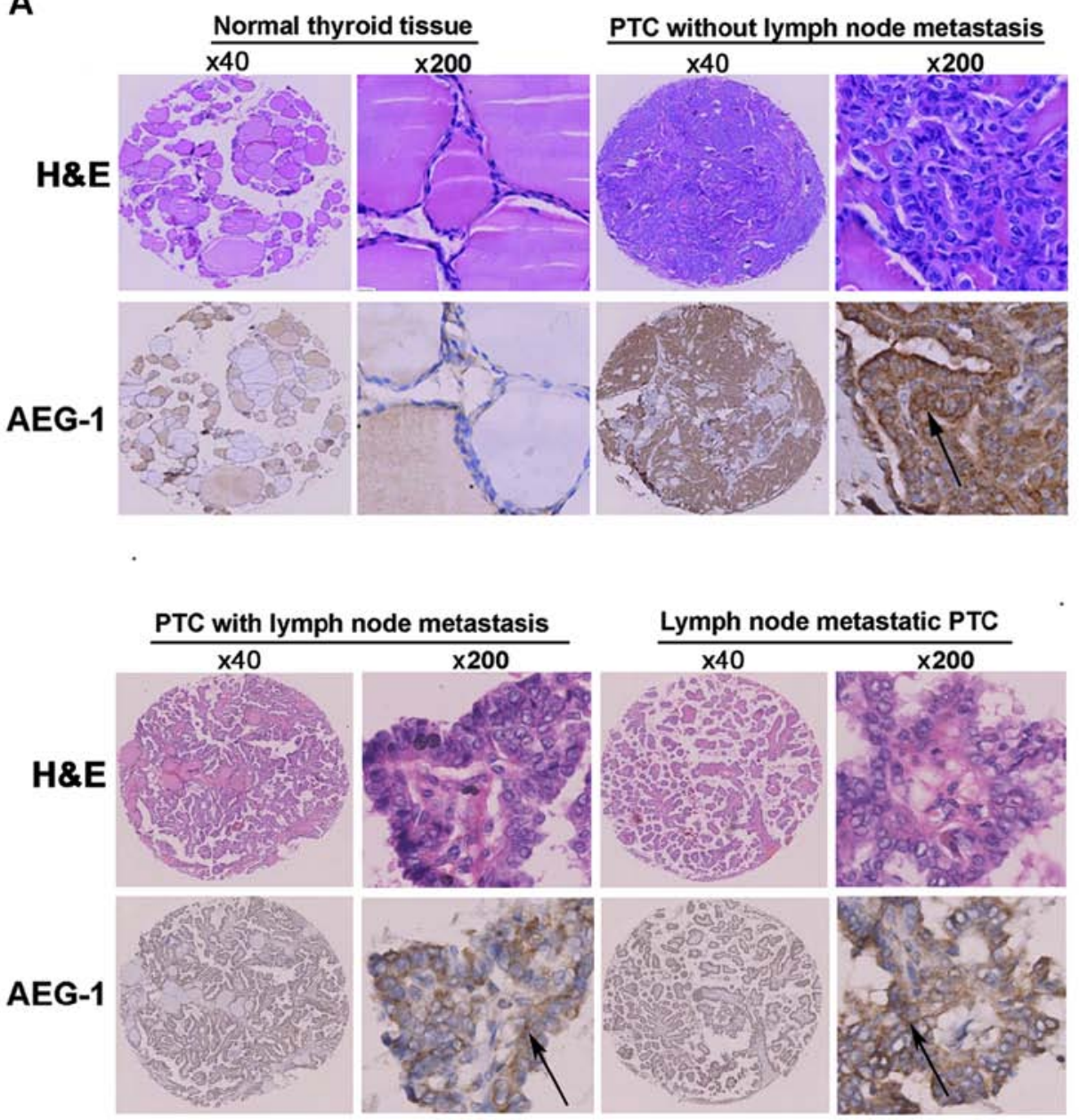

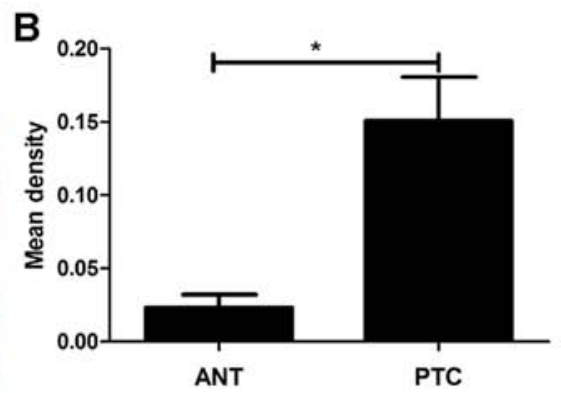

C
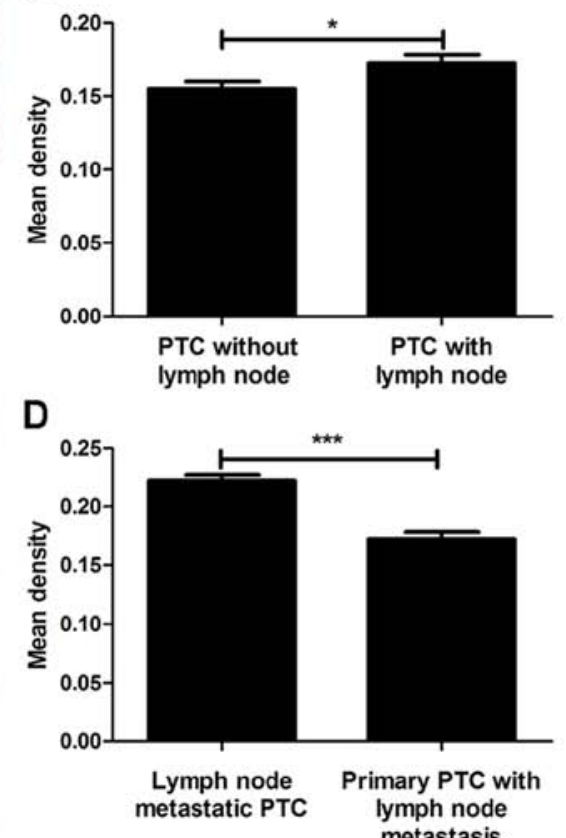

Figure 2. AEG-1 in PTC by immunohistochemical staining. (A) AEG-1 expression is shown in normal thyroid tissue, primary PTC without lymph node metastasis, primary PTC with lymph node metastasis and lymph node metastatic PTC, and the arrow shows the area of AEG-1 staining. (B) AEG-1 expression was elevated in PTC compared with that in ANT, ${ }^{*} \mathrm{P}<0.05$. (C) AEG-1 expression was elevated in PTC with lymph node metastasis compared with PTC without lymph node metastasis, ${ }^{*} \mathrm{P}<0.05$. (D) AEG-1 expression was elevated in lymph node metastatic PTC compared with respective primary $\mathrm{PTC}$, ${ }^{*} * \mathrm{P}^{\circ} \mathbf{0} .001$.

and anti-MMP9 antibody (Abgent) respectively. A reverse IP (IP with MMP9, western blotting with anti-AEG-1) was conducted as above.

Statistical analyses. All data are presented as mean \pm SD and analyzed using SPSS 16.0 statistics software. The significance of the observed differences was determined with the Student's t-test or one-way analysis of variance. The relations between AEG-1 and MMP2, MMP9 were analyzed by Spearman's correlation coefficients. $\mathrm{P}<0.05$ was considered to indicate a statistically significant difference.

\section{Results}

AEG-1 expression in fresh PTC and ANT. Western blotting was performed in eight pairs of fresh PTC tissue and ANT. Our results demonstrated that AEG-1 protein expression was higher in most PTC samples compared with that in paired ANT (Fig. 1A). The gray intensity of AEG-1 of PTC tissue is higher than ANT (P=0.011) (Fig. 1B). Real-time PCR analysis was carried out to further determine AEG-1 mRNA expression in eight pairs of fresh PTC and ANT. The results were consistent with protein expression (Fig. 1C). AEG-1 expression was upregulated in PTC.

AEG-1 expression in primary PTC, adjacent non-cancerous tissue and corresponding lymph node metastatic PTC tissue. We analyzed overall AEG-1 expression in primary PTC, their ANT and corresponding lymph node metastatic PTC tissues by performing IHC on 204 cases of PTC tissues (Fig. 2A). The 204 primary PTC included 119 cases without lymphatic metastasis and 85 cases with lymphatic metastasis. AEG-1 positive signals were located in the cytoplasm of cells by immunohistochemistry. The degree of AEG-1 positive staining in PTC cells were stronger than that in normal cells. The density of the immunohistochemical staining was measured by using the Image-Pro Plus 6.0 image analysis software. High levels of

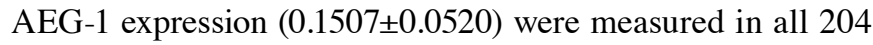
primary PTC sections. By contrast, AEG-1 was undetectable or only slightly detectable $(0.0236 \pm 0.0152)$ in the ANT sections. The result suggested a significantly higher level of AEG-1 expression in PTC tissues compared with the ANT $(\mathrm{P}=0.015$, Fig. 2B). The higher AEG-1 levels in PTC were because of the increased expression, but not more cells. Furthermore, we 
A

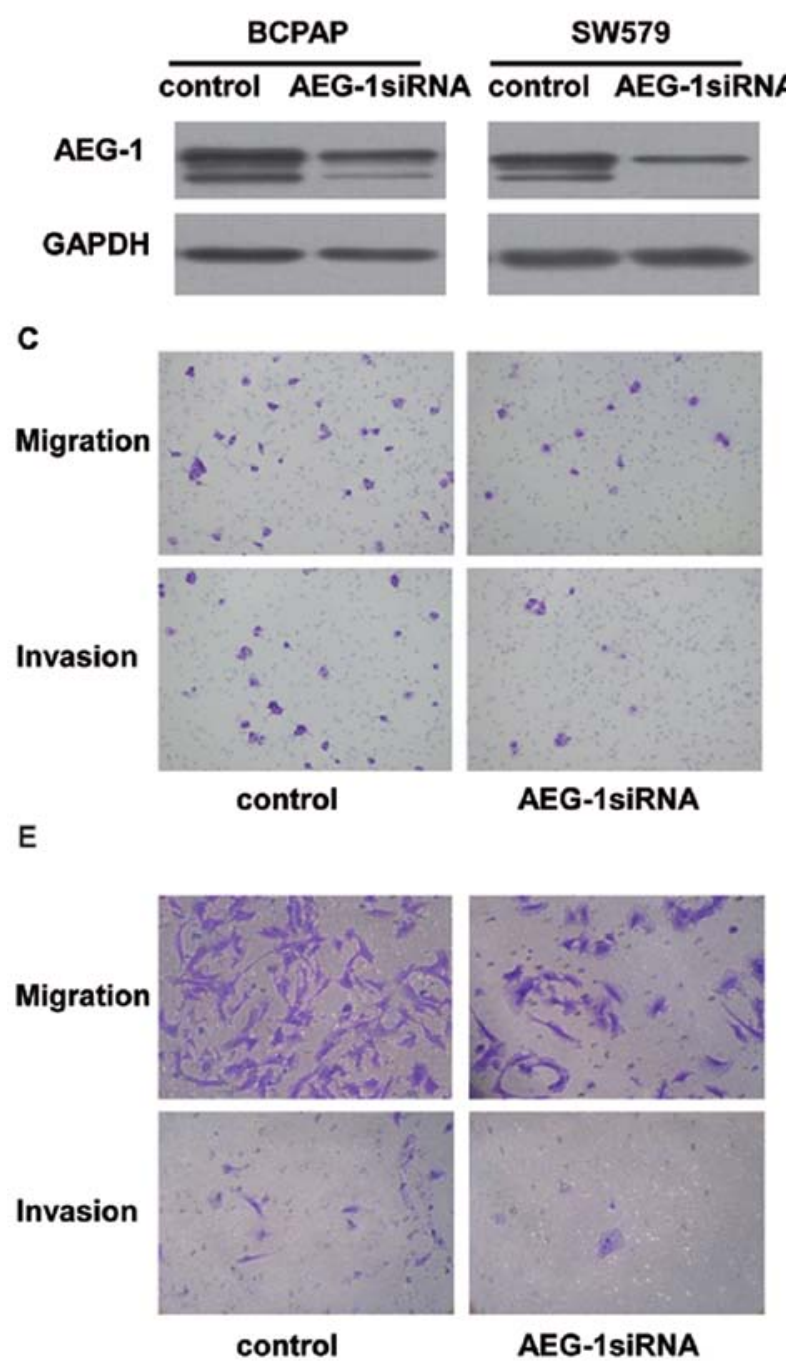

B

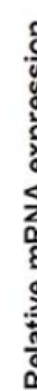

D

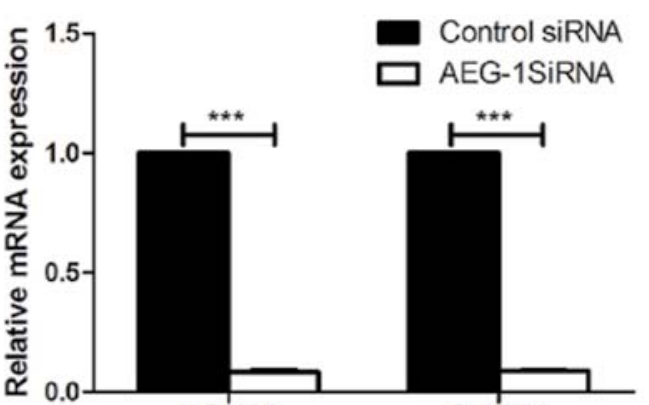

BCPAP

SW579

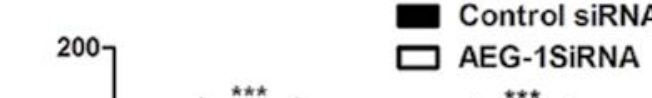

F
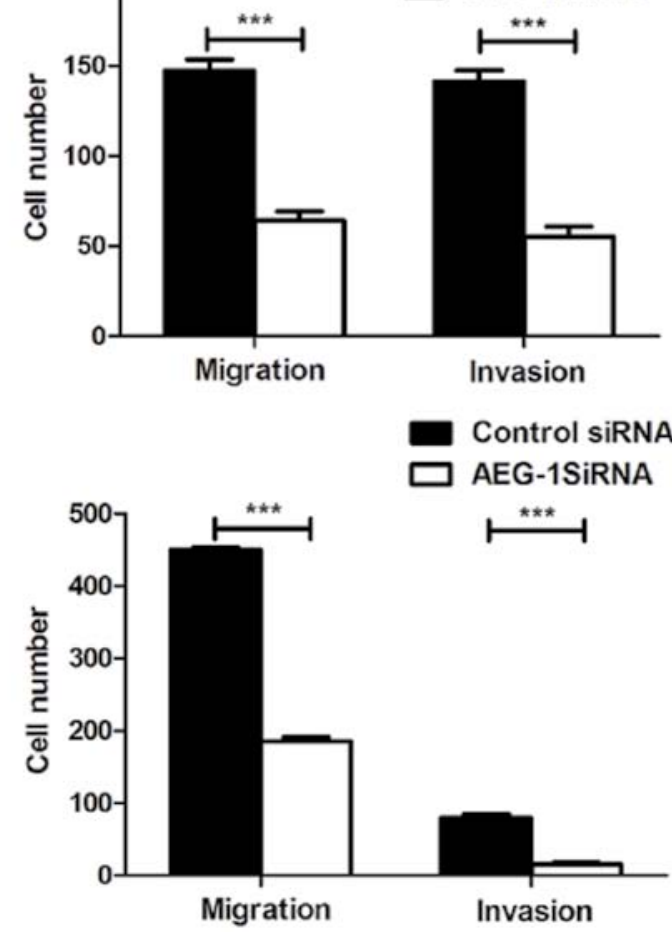

Figure 3. Knockdown of AEG-1 suppressed migration and invasion of thyroid cancer cells. (A) AEG-1 expression decreased in BCPAP and SW579 with AEG-1 siRNA compared with the negative control (NC). (B) The average quantification of AEG-1 mRNA by real-time RT-PCR analysis. Error bars represent standard deviations calculated from triple samples, ${ }^{* * *} \mathrm{P}<0.001$. (C and D) AEG-1 knockdown dramatically decreased migration and invasion of BCPAP compared with the control group by transwell assay, ${ }^{* * *} \mathrm{P}<0.001$. (E and F) AEG-1 silencing dramatically decreased invasion and migration of SW579 compared with the control group by transwell assay, ${ }^{* * *} \mathrm{P}<0.001$. Each experiment was performed three times in triplicate.

found the difference between PTC with lymph node metastasis ( 85 cases) and PTC without lymph node metastasis (119 cases). The mean density of former cases is $0.1622 \pm 0.0538$, while the density of latter cases is $0.1425 \pm 0.0492$ ( $\mathrm{P}=0.027$, Fig. 2C). In addition, the staining intensity of AEG-1 expression was significantly higher in lymph node metastatic PTC tissue $(0.2220 \pm 0.0439)$ compared with corresponding primary PTC $(0.1622 \pm 0.0545)(\mathrm{P}<0.001$, Fig. 2D).

The interrelationship between AEG-1 expression and clinicopathologic parameters. To determine the association between AEG-1 expression and clinicopathological implications of thyroid cancer, we conducted spearman's correlation according to age, gender, TNM stage, T classification, $\mathrm{N}$ and $\mathrm{M}$ classification (Table I). Statistical analysis exhibited that the expression of AEG-1 was significantly related to the $\mathrm{N}$ classification $(\mathrm{P}=0.007)$. However, no significant association of AEG-1 expression with the rest of clinical parameters was found.
AEG-1 increased migration and invasion of thyroid cancer cells in vitro. To explore the biological role of AEG-1 on the progression of PTC, we used small interfering RNA (siRNA) approaches to reduce AEG-1 expression in BCPAP and SW579 cell lines. AEG-1 siRNA successfully knocked down AEG-1 expression at protein levels (Fig. 3A) and mRNA levels (Fig. 3B), using western blotting and real-time PCR. Transwell cell migration assay revealed that silencing of AEG-1 expression significantly inhibited the migratory ability of BCPAP and SW579 cell lines. Moreover, transwell matrix penetration assay showed that knockdown of AEG-1 significantly reduced the invasive properties of both cell lines (Fig. 3C-F). Taken together, these results suggest that AEG1 promotes migration and invasion of PTC cells.

AEG-1-mediated cancer cell migration and invasion is linked to MMP2 and MMP9. The association between the expression levels of AEG-1 and MMP2 or MMP9 was examined 
A

H\&E

AEG-1
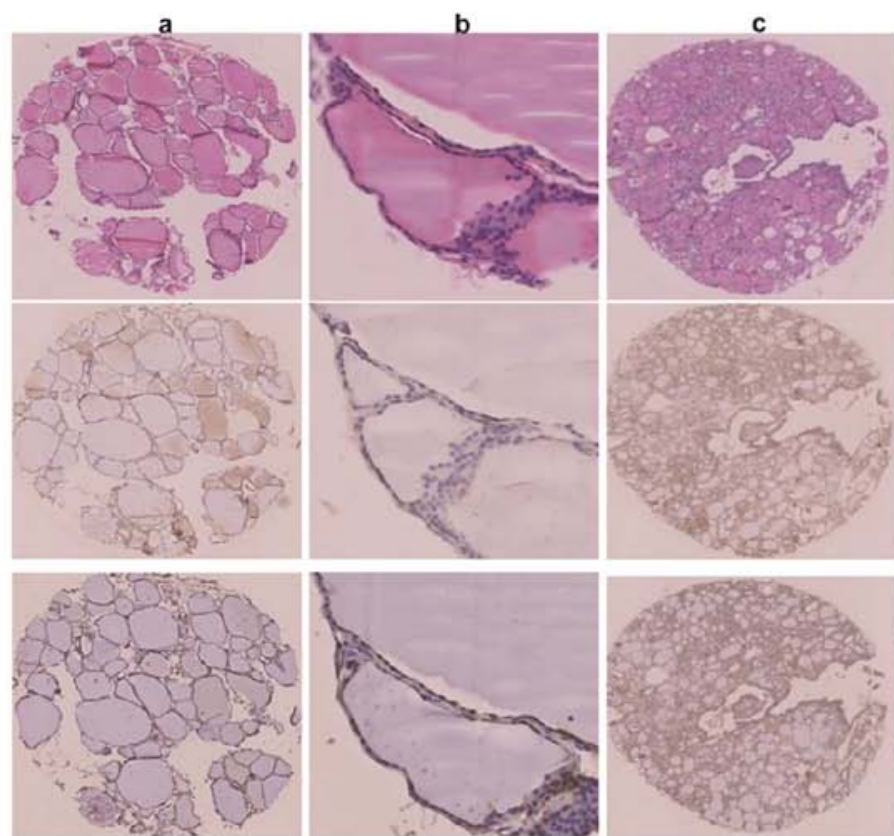

MMP2
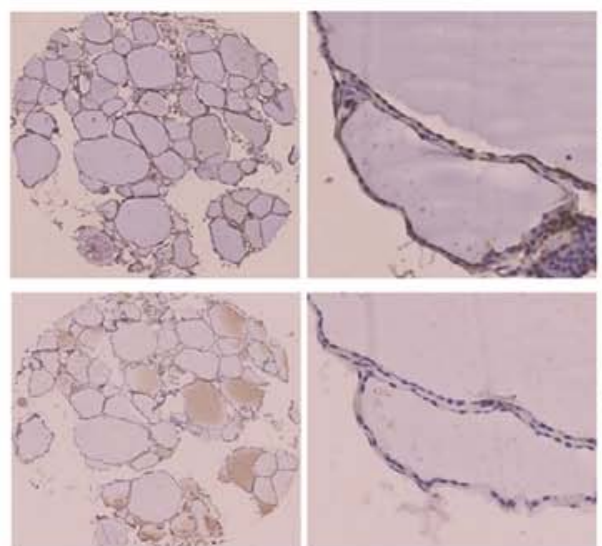

B

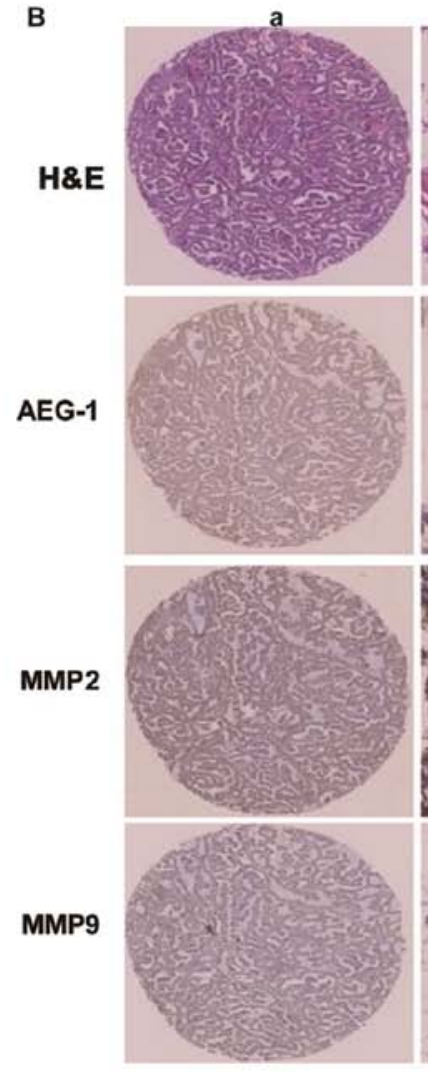

H\&E
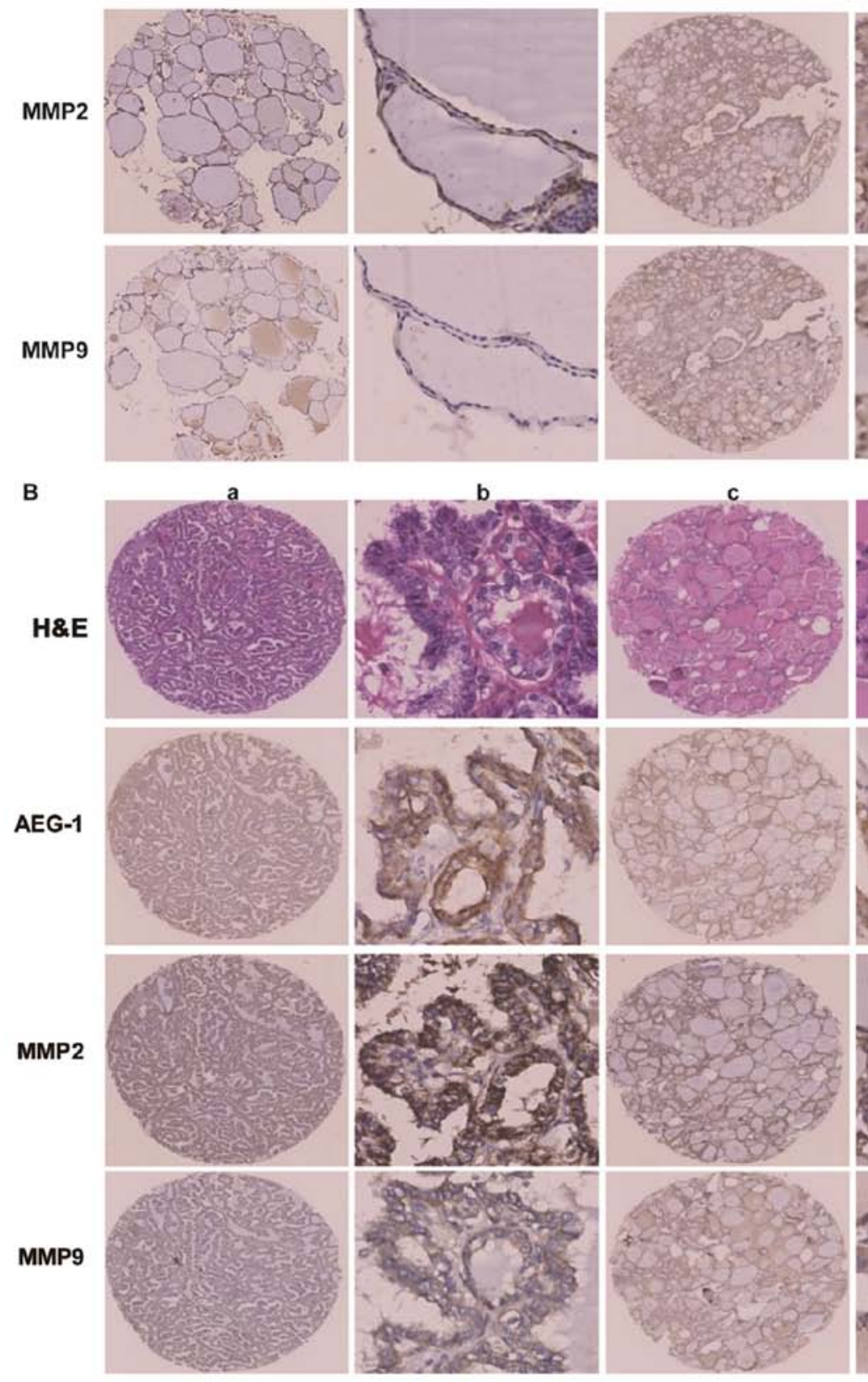
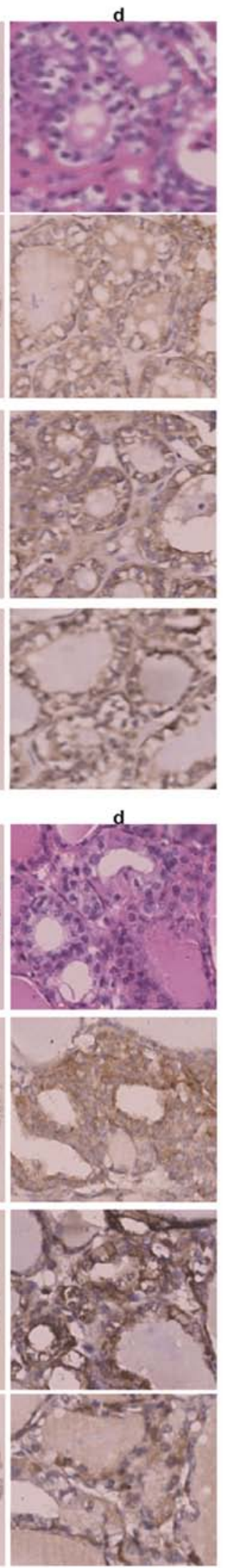

Figure 4. AEG-1 expression positively correlated with MMP2 and MMP9 expression by immunohistochemistry. (A) AEG-1, MMP2 and MMP9 expressed lower level in normal thyroid tissue ( $a$ and b) than that in primary PTC without lymph node metastasis ( $c$ and d); a and c, x40; b and d, x200. (B) Both PTC with lymph node metastasis ( $a$ and b) and lymph node metastatic PTC ( $\mathrm{c}$ and d) showed strong expression of AEG-1, MMP2 and MMP9, a and c, x40; b and d, x200.

in all 204 pairs of PTC tissues. PTC samples with high-level AEG-1 expression exhibited strong MMP2 staining signals, whereas MMP2 expression in specimens with low AEG-1 levels was also low or absent (Fig. 4A). The outcome was 
A

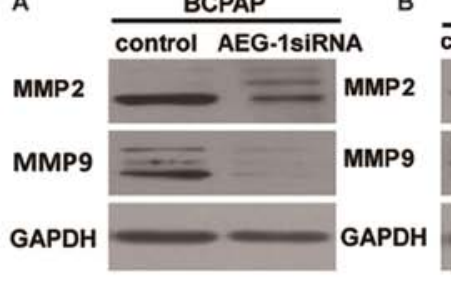

C

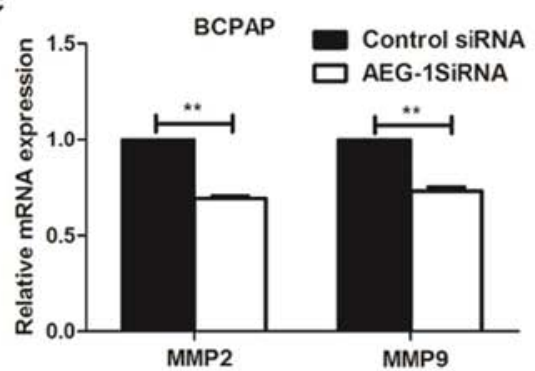

D
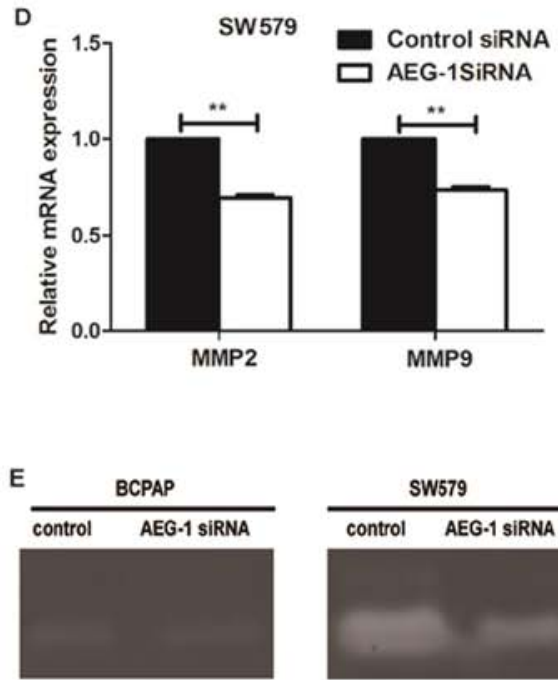
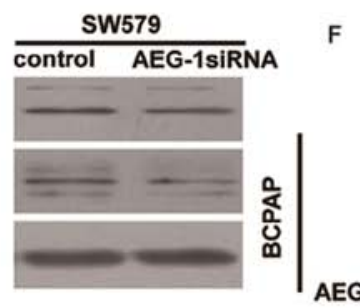

$F$

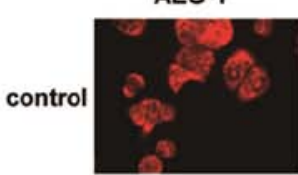

AEG-1
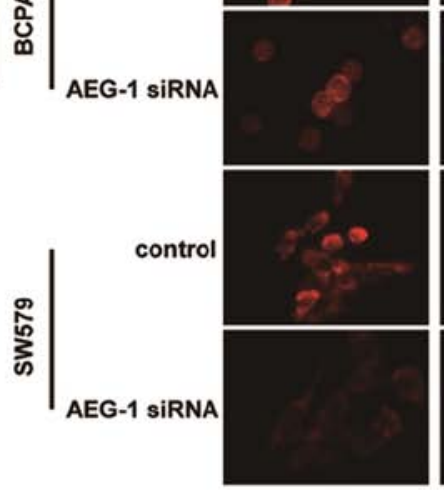

G

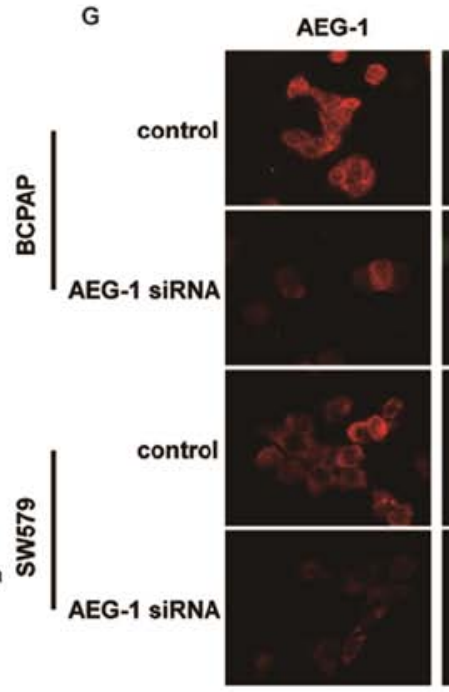

MMP2
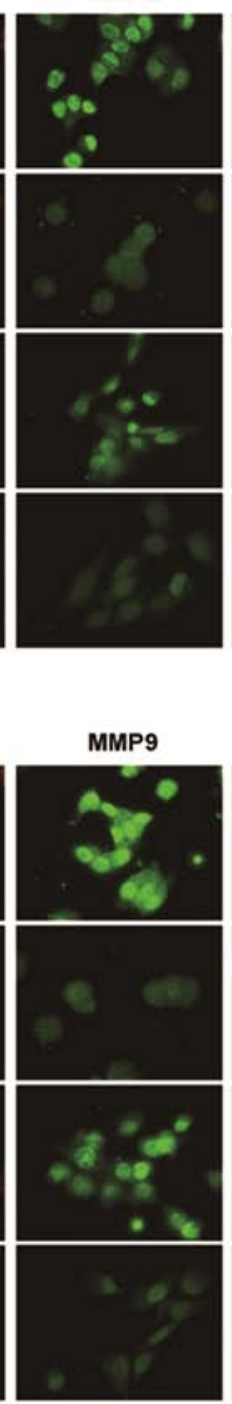

DAPI
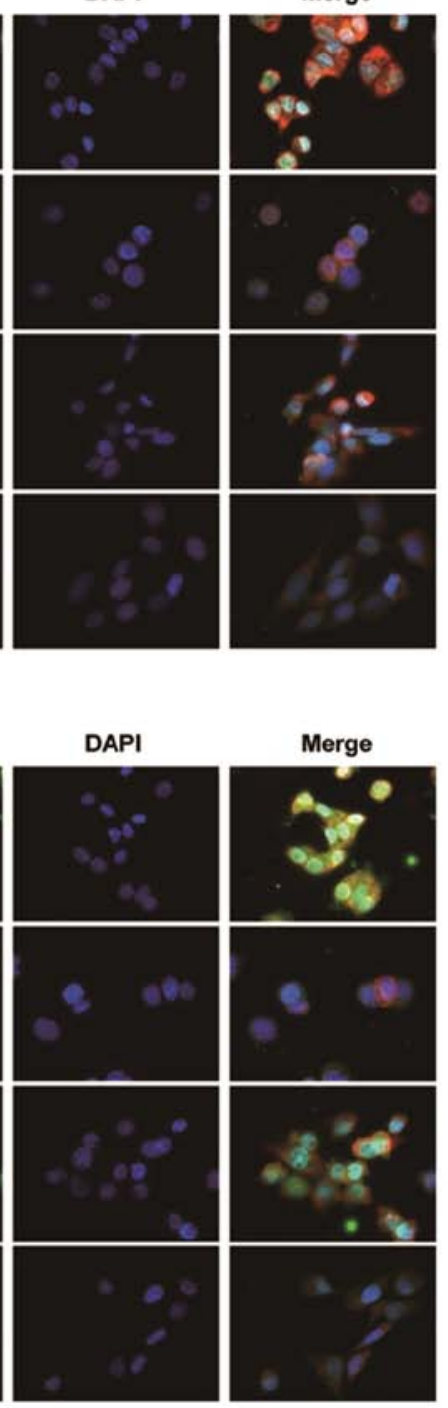

Merge

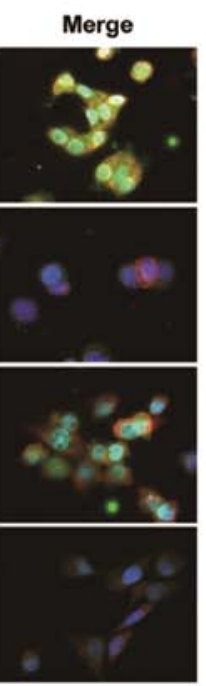

Figure 5. Knockdown of AEG-1 represses MMP2 and MMP9 expression in BCPAP and SW579 cells. (A) AEG-1 knockdown decreased MMP2 and MMP9 expression by western blotting in BCPAP. (B) AEG-1 knockdown decreased MMP2 and MMP9 expression by western blotting in SW579. (C) AEG-1 knockdown decreased MMP2 and MMP9 expression by PT-PCR in BCPAP. Error bars represent standard deviations calculated from triple samples ** $<0.01$, ${ }^{* * *} \mathrm{P}<0.001$. (D) AEG-1 knockdown decreased MMP2 and MMP9 expression by PT-PCR in SW579. Error bars represent standard deviations calculated from triple samples ${ }^{* *} \mathrm{P}<0.01,{ }^{* * *} \mathrm{P}<0.001$. (E) AEG-1 knockdown decreased MMP2 and MMP9 activity by zymography in SW579, while the results in BCPAP showed no obvious difference. The white bands represent MMP2/9-mediated gelatin digestion. (F) AEG-1 knockdown suppressed MMP2 and MMP9 expression by immunofluorescence staining assay in both BCPAP and SW579. Immunofluorescence staining x200. Each experiment was performed three times in triplicate.

the same when AEG-1 and MMP9 expression was analyzed (Fig. 4B). Spearman correlation analysis showed positive correlations between AEG-1 and MMP2, AEG-1 and MMP9 expression in the tested tissue samples $(r=0.160 ; \mathrm{P}=0.022$; $\mathrm{r}=0.140 ; \mathrm{P}=0.045)$. It suggested that AEG-1 overexpression was clinically relevant to upregulation of MMP2 and MMP9 in human PTC tissue.

Western blot and real-time PCR analysis were done to determine the expression levels of MMP2 and MMP9 in cell lines transfected with AEG-1 siRNA. Knockdown of AEG-1 repressed MMP2 and MMP9 in protein and mRNA expression in BCPAP and SW579 cells (Fig. 5A-D). Consistent with western blot and RT-PCR data, immunofluorescence showed that AEG-1 siRNA inhibited the expression of MMP2 and MMP9 than negative control (Fig. 5F-G). Moreover, the activities of MMP2 and MMP9 in SW579 were found to be reduced by AEG-1 siRNA using zymography assay, while the results in BCPAP showed no obvious difference (Fig. 5E). It indicated that AEG-1 could regulate the activities of MMP2 and MMP9.

AEG-1 interacts with MMP9. To further study whether AEG-1 interacts with MMP2 and MMP9 in thyroid cancer, we conducted co-immunoprecipitation assay on BCPAP and SW579 cell lines. Our result showed that AEG-1 interacted with MMP9 in vitro (Fig. 6), but there was no interaction between AEG-1 and MMP2.

AEG-1 mediates aggressiveness of thyroid cancer via the $N F-\kappa B$ pathway. We performed western blot analysis and image analysis to illustrate whether AEG-1 mediated invasion and metastasis of thyroid cancer by modulating the NF- $\kappa \mathrm{B}$ pathway. Our results showed that the levels of phospho-p65 
A

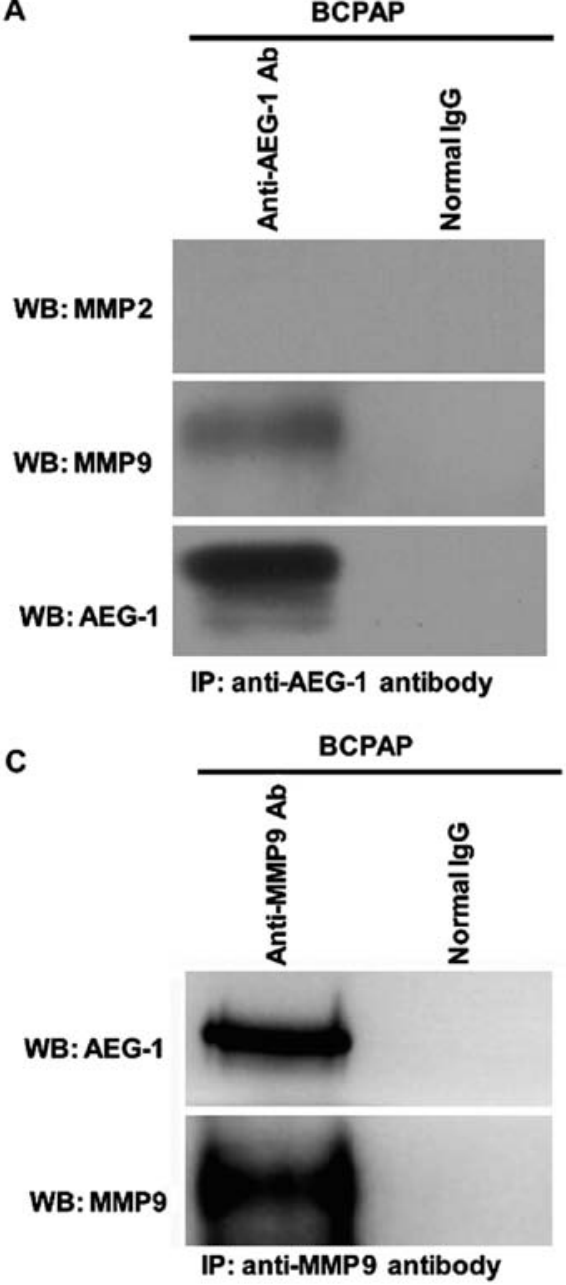

B

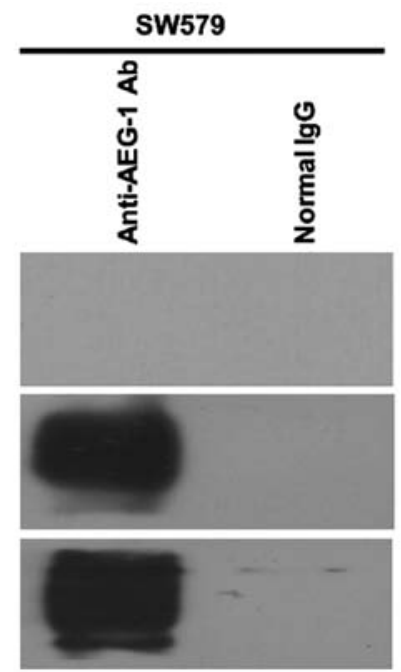

IP: anti-AEG-1 antibody

SW579

D

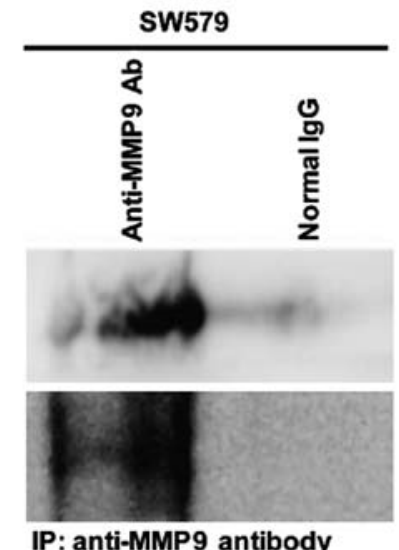

Figure 6. AEG-1 interacts with MMP9 in vitro by immunoprecipitation in BCPAP and SW579. (A and B) Immunoprecipitation was performed in BCPAP and SW579 cell lines with either normal IgG or anti-AEG-1 antibody and immunoblotting was performed by anti-MMP2, anti-MMP9 and anti-AEG-1 antibody. (C and D) A reverse IP was performed in BCPAP and SW579 cell lines with either normal IgG or anti-MMP9 antibody and immunoblotting was performed by anti-AEG-1 and anti-MMP9 antibody. Each experiment was performed three times in triplicate.

were significantly downregulated by AEG-1 siRNA ( $\mathrm{P}=0.007$ in BCPAP; $\mathrm{P}=0.004$ in SW579), with no significant changes in total $\mathrm{p} 65$ (a subunit of NF- $\mathrm{kB}$ ) levels $(\mathrm{P}=0.552$ in BCPAP; $\mathrm{P}=0.229$ in SW579) (Fig. 7). This result demonstrate that AEG-1 could influence the development thyroid cancer at least partially by the NF- $\kappa \mathrm{B}$ signaling pathway.

\section{Discussion}

The diverse roles of AEG-1 in tumor progression in most cancers are now being elucidated. For instance, AEG-1 is essential for NF- $\mathrm{\kappa B}$ activation, hepatocarcinogenesis and shaping the tumor microenvironment for hepatocellular carcinoma development (18). Moreover, AEG-1 is overexpressed in a great portion of epithelial ovarian cancer patients with peritoneal dissemination and/or lymph node metastasis. AEG-1 may be clinically useful for predicting metastasis in epithelial ovarian cancer (19). However, the role of AEG-1 in thyroid cancer is confused. In this study, we found that the expression of AEG-1 was elevated in PTC tissues compared with that in normal thyroid controls. At the same time, the higher expression of AEG-1 was correlated with lymph node metastasis in thyroid carcinoma. Moreover metastatic lesions displayed significantly higher AEG-1 expression than primary lesions in PTC. So our results suggest that AEG-1 might play an important role in the progression and metastasis of PTC, which is consistent with other reports. AEG-1 may be a useful metastatic predictor in PTC.

Recent studies have documented that AEG-1 insights into a novel gene involved in tumor progression and metastasis. The function of MMPs was believed to not only degrade the extracellular matrix but also involve in development, angiogenesis, inflammation, cancer progression, and especially in promoting migration and invasion of cancer cells (20-22). Research has shown that MMP2 and MMP9 were involved in AEG-1-mediated invasion of glioma cells (23). Moreover, AEG-1 contributes to the progression and invasion of glioma by enhancing MMP9 transcription (24). MMP-1 may be a downstream factor of AEG-1 in determining the invasion and metastasis in head and neck squamous cell carcinoma (25). At the same time, our previous study showed that AEG-1mediated carcinogenesis and invasiveness might be through upregulating MMP2 in osteosarcoma (26). Epidermal growth factor-containing fibulin-like extracellular matrix protein 1 


\section{control AEG-1siRNA control AEG-1siRNA}

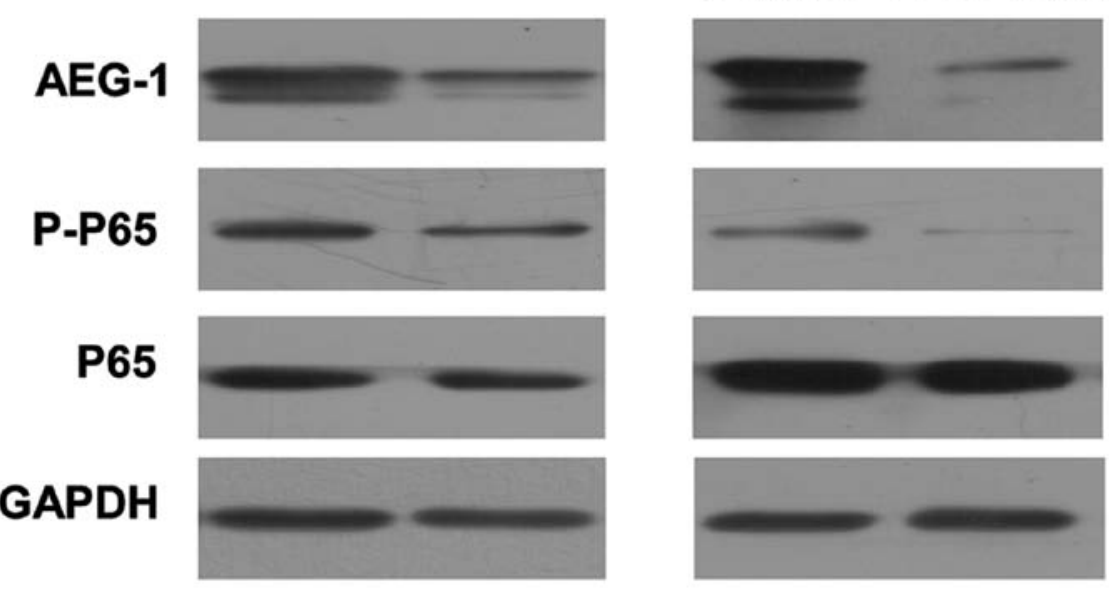

B

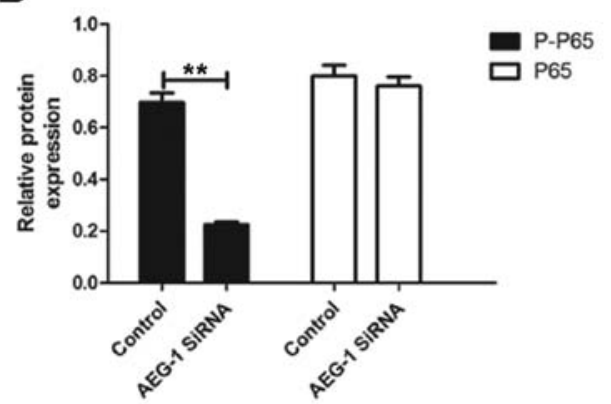

C

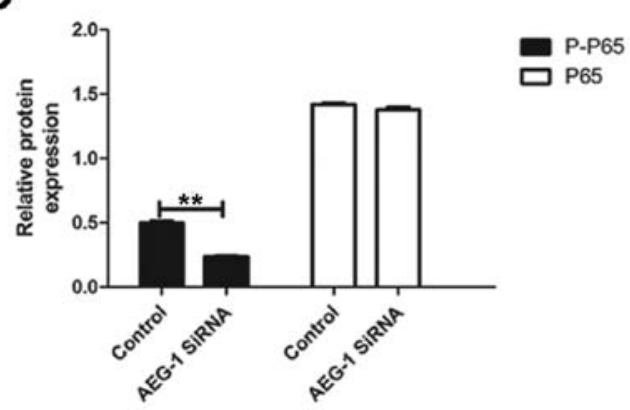

Figure 7. AEG-1 affects NF-kB pathway in BCPAP and SW579. (A) Western blot analysis of the expression of AEG-1, phospho-p65, total p65, in control and AEG-1-infected thyroid cancer cell lines. Each experiment was performed three times in triplicate. (B) The gray intensity of phospho-p65 of AEG-1-infected BCPAP was lower than control ( $\mathrm{P}=0.007)$, with no difference of total p65 ( $\mathrm{P}=0.552),{ }^{* *} \mathrm{P}<0.01$. (C) The gray intensity of phospho-p65 of AEG-1-infected SW579 was lower than control $(\mathrm{P}=0.004)$, with no difference of total $\mathrm{p} 65(\mathrm{P}=0.229),{ }^{* *} \mathrm{P}<0.01$.

played a part as the mediator between AEG-1 and MMP2 in metastasis of osteosarcoma (27). Since studies showed that AEG-1-mediated metastasis was closely related to MMP2/9, we tried to find out the relationship between AEG-1 and MMP2/9 in the progression of PTC. In our study, AEG-1 was specifically upregulated in thyroid cancer and associated with the invasion and migration in thyroid cancer. Additionally, we found that AEG-1 siRNA inhibited the activation of MMP2 and MMP9 in SW579. Curiously, the activation of MMP2 and MMP9 in BCPAP did not show the same obvious change, which might be due to the weak metastasis capacity of BCPAP. So our data suggested that AEG-1-mediated migratory and invasiveness might be through upregulating MMP2 and MMP9 in thyroid cancer.

Of note, we found that AEG-1 could directly interact with MMP9 through Co-immunoprecipitation (Co-IP) test. To our knowledge, this was the first report to show that AEG-1 interacted with MMP9. Previous studies had already exhibited that AEG-1 exerted multiple functions by interacting with other proteins in protein complexes, such as NF- $\mathrm{KB}(13,14)$, PLZF (28), BCCIP $\alpha$ (29), SND1 (30) and $\beta$-catenin (31). For example, AEG-1 promoted tumor cell migration and invasion through activation of the transcription factor of $N F-\kappa B$ by directly interacting with the p65 subunit of NF- $\mathrm{NB}(13,14)$. Staphylococcal nuclease domain containing 1 (SND1), a nuclease in the RNA-induced silencing complex (RISC), facilitating RNAi-mediated gene silencing, was revealed as an AEG-1 interacting protein (30). The inhibition of enzymatic activity of SND1 abrogates AEG-1 function in regulating cell growth and proliferation. Now we found that MMP9 was also an AEG-1-interacting protein. What effect it has on tumor progression is not yet known. It may affect the stability of MMP9 structure, or promote the function of MMP9 by the formation of the protein complex. Further studies are required to confirm these hypotheses.

$\mathrm{NF}-\kappa \mathrm{B}$ is responsible for the induction of MMP9 expression through targeting the promoter directly (32). AEG-1 interacts with cyclic AMP-responsive element binding protein-binding protein $(\mathrm{CBP})$, indicating that it might act as a bridging factor between $\mathrm{NF}-\kappa \mathrm{B}, \mathrm{CBP}$, and the basal transcription machinery (14). The above indicated that AEG-1 could indi-

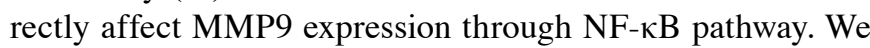
found that downregulating AEG-1 could significantly reduce the expression of pp65, a subunit of NF- $\kappa \mathrm{B}$, which supported our hypothesis that AEG-1 might indirectly mediate MMP9 expression through the $\mathrm{NF}-\kappa \mathrm{B}$ pathway. In addition, other research has shown the direct interaction between AEG-1 and p65 (13). We found the AEG-1-MMP9 interaction. There is the possibility that the functional complex was formed by AEG-1, p65 and MMP9. Whether AEG-1 acts as a bridging molecule 
between NF- $\mathrm{NB}$ and MMP9 is of interest for further study. Perhaps it is a new possible mechanism that AEG-1 promotes tumor cell migration and invasion by MMP9.

In summary, our data showed that high expression of AEG-1 played a crucial role of invasion and metastasis in thyroid cancer through MMP2 and 9. At the same time, the activation of $\mathrm{NF}-\kappa \mathrm{B}$ pathway might be a possible working mechanism. Moreover, the new finding of the interaction of AEG-1 and MMP9 is another potential form that AEG-1 promoted tumor cell migration and invasion.

\section{Acknowledgements}

This work was supported by the Foundation of China National Natural Science (nos. 81172232, 81372865 and 81402465) and the Foundation of China Guangdong Science and Technology (no. 2013B021800128). The authors thank Mr. Yuefeng Wang (Department of Pathology, the First Affiliated Hospital of Sun Yat-Sen University) for his assistance with zymography analyses.

\section{References}

1. Brito JP, Hay ID and Morris JC: Low risk papillary thyroid cancer. BMJ 348: g3045, 2014

2. Grubbs EG and Evans DB: Role of lymph node dissection in primary surgery for thyroid cancer. J Natl Compr Canc Netw 5: 623-630, 2007

3. Mazzaferri EL and Jhiang SM: Long-term impact of initial surgical and medical therapy on papillary and follicular thyroid cancer. Am J Med 97: 418-428, 1994.

4. Zaydfudim V, Feurer ID, Griffin MR and Phay JE: The impact of lymph node involvement on survival in patients with papillary and follicular thyroid carcinoma. Surgery 144: 1070-1077, discussion 1077-1078, 2008.

5. Su ZZ, Kang DC, Chen Y, Pekarskaya O, Chao W, Volsky DJ and Fisher PB: Identification and cloning of human astrocyte genes displaying elevated expression after infection with HIV-1 or exposure to HIV-1 envelope glycoprotein by rapid subtraction hybridization, RaSH. Oncogene 21: 3592-3602, 2002.

6. Kang DC, Su ZZ, Sarkar D, Emdad L, Volsky DJ and Fisher PB: Cloning and characterization of HIV-1-inducible astrocyte elevated gene-1, AEG-1. Gene 353: 8-15, 2005.

7. Yoo BK, Emdad L, Lee SG, Su ZZ, Santhekadur P, Chen D, Gredler R, Fisher PB and Sarkar D: Astrocyte elevated gene-1 (AEG-1): A multifunctional regulator of normal and abnormal physiology. Pharmacol Ther 130: 1-8, 2011.

8. Luo Y, Zhang X, Tan Z, Wu P, Xiang X, Dang Y and Chen G: Astrocyte elevated gene-1 as a novel clinicopathological and prognostic biomarker for gastrointestinal cancers: A metaanalysis with 2999 patients. PLoS One 10: e0145659, 2015.

9. Emdad L, Das SK, Dasgupta S, Hu B, Sarkar D and Fisher PB: AEG-1/MTDH/LYRIC: Signaling pathways, downstream genes, interacting proteins, and regulation of tumor angiogenesis. Adv Cancer Res 120: 75-111, 2013.

10. Li C, Wu X, Zhang W, Li J, Liu H, Hao M, Wang J, Zhang H, Yang $\mathrm{G}$, Hao M, et al: AEG-1 promotes metastasis through downstream AKR1C2 and NF1 in liver cancer. Oncol Res 22: 203-211, 2014

11. Sarkar D, Emdad L, Lee SG, Yoo BK, Su ZZ and Fisher PB: Astrocyte elevated gene-1: Far more than just a gene regulated in astrocytes. Cancer Res 69: 8529-8535, 2009.

12. Song L, Li W, Zhang H, Liao W, Dai T, Yu C, Ding X, Zhang L and Li J: Over-expression of AEG-1 significantly associates with tumour aggressiveness and poor prognosis in human non-small cell lung cancer. J Pathol 219: 317-326, 2009.

13. Emdad L, Sarkar D, Su ZZ, Randolph A, Boukerche H, Valerie K and Fisher PB: Activation of the nuclear factor kappaB pathway by astrocyte elevated gene-1: Implications for tumor progression and metastasis. Cancer Res 66: 1509-1516, 2006.
14. Sarkar D, Park ES, Emdad L, Lee SG, Su ZZ and Fisher PB: Molecular basis of nuclear factor-kappaB activation by astrocyte elevated gene-1. Cancer Res 68: 1478-1484, 2008.

15. Pan Y, Guo X, Yang Z, Chen S, Lei Y, Lin M, Wang L, Feng C, and $\mathrm{Ke} \mathrm{Z}$ : AEG-1 activates Wnt/PCP signaling to promote metastasis in tongue squamous cell carcinoma. Oncotarget 7: 2093-2104, 2016.

16. Fabien N, Fusco A, Santoro M, Barbier Y, Dubois PM and Paulin C: Description of a human papillary thyroid carcinoma cell line. Morphologic study and expression of tumoral markers. Cancer 73: 2206-2212, 1994.

17. Fogh J, Wright WC and Loveless JD: Absence of HeLa cell contamination in 169 cell lines derived from human tumors. J Natl Cancer Inst 58: 209-214, 1977.

18. Robertson CL, Srivastava J, Siddiq A, Gredler R, Emdad L, Rajasekaran D, Akiel M, Shen XN, Guo C, Giashuddin S, et al: Genetic deletion of AEG-1 prevents hepatocarcinogenesis. Cancer Res 74: 6184-6193, 2014.

19. Li C, Liu J, Lu R, Yu G, Wang X, Zhao Y, Song H, Lin P, Sun X, Yu X, et al: AEG -1 overexpression: A novel indicator for peritoneal dissemination and lymph node metastasis in epithelial ovarian cancers. Int J Gynecol Cancer 21: 602-608, 2011.

20. Boire A, Covic L, Agarwal A, Jacques S, Sherifi S and Kuliopulos A: PAR1 is a matrix metalloprotease-1 receptor that promotes invasion and tumorigenesis of breast cancer cells. Cell 120: 303-313, 2005.

21. McQuibban GA, Gong JH, Wong JP, Wallace JL, Clark-Lewis I and Overall CM: Matrix metalloproteinase processing of monocyte chemoattractant proteins generates CC chemokine receptor antagonists with anti-inflammatory properties in vivo. Blood 100: 1160-1167, 2002.

22. Yu Q and Stamenkovic I: Cell surface-localized matrix metalloproteinase-9 proteolytically activates TGF-beta and promotes tumor invasion and angiogenesis. Genes Dev 14: 163-176, 2000.

23. Emdad L, Sarkar D, Lee SG, Su ZZ, Yoo BK, Dash R, Yacoub A, Fuller CE, Shah K, Dent P, et al: Astrocyte elevated gene-1: A novel target for human glioma therapy. Mol Cancer Ther 9: 79-88, 2010 .

24. Liu L, Wu J, Ying Z, Chen B, Han A, Liang Y, Song L, Yuan J, $\mathrm{Li} \mathrm{J}$ and $\mathrm{Li} \mathrm{M}$ : Astrocyte elevated gene-1 upregulates matrix metalloproteinase- 9 and induces human glioma invasion. Cancer Res 70: 3750-3759, 2010.

25. Wang YP, Liu IJ, Chiang CP and Wu HC: Astrocyte elevated gene-1 is associated with metastasis in head and neck squamous cell carcinoma through p65 phosphorylation and upregulation of MMP1. Mol Cancer 12: 109, 2013.

26. Wang F, Ke ZF, Sun SJ, Chen WF, Yang SC, Li SH, Mao XP and Wang LT: Oncogenic roles of astrocyte elevated gene-1 (AEG-1) in osteosarcoma progression and prognosis. Cancer Biol Ther 12: 539-548, 2011.

27. Wang Z, Cao CJ, Huang LL, Ke ZF, Luo CJ, Lin ZW, Wang F, Zhang YQ and Wang LT: EFEMP1 promotes the migration and invasion of osteosarcoma via MMP-2 with induction by AEG-1 via NF-кB signaling pathway. Oncotarget 6: 14191-14208, 2015.

28. Thirkettle HJ, Mills IG, Whitaker HC and Neal DE: Nuclear LYRIC/AEG-1 interacts with PLZF and relieves PLZF-mediated repression. Oncogene 28: 3663-3670, 2009.

29. Ash SC, Yang DQ and Britt DE: LYRIC/AEG-1 overexpression modulates BCCIPalpha protein levels in prostate tumor cells. Biochem Biophys Res Commun 371: 333-338, 2008.

30. Yoo BK, Chen D, Su ZZ, Gredler R, Yoo J, Shah K, Fisher PB and Sarkar D: Molecular mechanism of chemoresistance by astrocyte elevated gene-1. Cancer Res 70: 3249-3258, 2010.

31. Zhang F, Yang Q, Meng F, Shi H, Li H, Liang Y and Han A: Astrocyte elevated gene-1 interacts with $\beta$-catenin and increases migration and invasion of colorectal carcinoma. Mol Carcinog 52: 603-610, 2013.

32. Farina AR, Tacconelli A, Vacca A, Maroder M, Gulino A and Mackay AR: Transcriptional up-regulation of matrix metalloproteinase-9 expression during spontaneous epithelial to neuroblast phenotype conversion by SK-N-SH neuroblastoma cells, involved in enhanced invasivity, depends upon GT-box and nuclear factor kappaB elements. Cell Growth Differ 10: 353-367, 1999. 